\title{
The Catabolism of Cholesterol in vitro
}

\author{
FORMATION OF $3 \alpha, 7 \alpha, 12 \alpha$-TRIHYDROXY-5 $\beta$-CHOLESTANOIC ACID FROM \\ CHOLESTEROL BY RAT LIVER
}

\author{
By D. MENDELSOHN AND L. MENDELSOHN \\ Department of Chemical Pathology, Witwatersrand University Medical School, Johannesburg, \\ South Africa
}

(Received 10 March 1969)

\begin{abstract}
1. Both 25-D- and 25-L-3 $\alpha, 7 \alpha, 12 \alpha$-trihydroxy-5 $\beta$-cholestanoic acid were isolated from the gall-bladder bile of Crocodylus niloticus. 2. The catabolism of cholesterol to 25-D- and 25-L-3 $\alpha, 7 \alpha, 12 \alpha$-trihydroxy-5 $\beta$-cholestanoic acid respectively was studied by using a rat liver preparation in vitro. The results show that rat liver can metabolize cholesterol to both forms of $3 \alpha, 7 \alpha, 12 \alpha$-trihydroxy-5 $\beta$-cholestanoic acid. However, a preference was noted for the formation from $\left[4^{-14} \mathrm{C}\right]$ cholesterol of $3 \alpha, 7 \alpha, 12 \alpha$-trihydroxy-5 $\beta$-cholestanoic acid (25-D), which was isolated from the incubations with a specific radioactivity about four times that of $3 \alpha, 7 \alpha, 12 \alpha$ trihydroxy-5 $\beta$-cholestanoic acid (25-L). 3. The results indicate that $3 \alpha, 7 \alpha, 12 \alpha-$ trihydroxy-5 $\beta$-cholestanoic acid is a normal intermediate in the biosynthesis of bile acids from cholesterol in the rat.
\end{abstract}

Kurauti \& Kazuno (1939) were the first to isolate an acidic sterol from the bile of the frog Rana catesbiana that they named ' $\alpha$-trihydroxybisnorsterocholanic acid'. Later Haslewood (1952) obtained a $\mathrm{C}_{27}$ acid from the bile of Alligator mississippiensis and showed that it was identical with the ' $\alpha$-trihydroxybisnorsterocholanic acid'described by Kurauti \& Kazuno (1939). After elucidation of its structure (Bridgwater \& Haslewood, 1952), the acid was renamed $3 \alpha, 7 \alpha, 12 \alpha$-trihydroxycoprostanic acid (THCA*). It was then demonstrated by Bridgwater \& Lindstedt (1957) that this compound could be efficiently converted into cholic acid by the bilefistulated rat, suggesting that it might be an intermediate in bile acid formation from cholesterol in this species. Since the fact that THCA is an effective precursor of cholic acid in the bile-fistulated rat does not prove that the former is an intermediate in bile acid genesis from cholesterol, an attempt was made to obtain further evidence to test the validity of the above statement. The present paper describes the formation of THCA from cholesterol by a rat liver preparation in vitro.

\section{MATERIALS AND METHODS}

Extraction of THCA from crocodile bile. Bile obtained from the gall bladder of Crocodylus niloticus was poured into 2 vol. of ethanol, well stirred and left at room temperature

* Abbreviation : THCA, $3 \alpha, 7 \alpha, 12 \alpha$-trihydroxycoprostanic acid $(3 \alpha, 7 \alpha, 12 \alpha$-trihydroxy-5 $\beta$-cholestanoic acid).

1 for a few hours. After filtration, the precipitate was refluxed under ethanol for $2 \mathrm{hr}$. and the combined ethanol filtrates were evaporated to dryness. The resulting brown gummy mass was dissolved in a small volume of water, made approx. $7 \mathrm{M}$ with respect to $\mathrm{NaOH}$ and then heated in an autoclave at $20 \mathrm{lb}$./in. ${ }^{2}$ for $16 \mathrm{hr}$. After cooling, the mixture was adjusted to approx. $\mathrm{pH} 2$ with conc. $\mathrm{HCl}$, at which stage more water was added because the consistency was too thick. The mix was exhaustively extracted with ethyl acetate, and the combined extracts were washed twice with water before evaporation to dryness. The brownish residue was triturated several times with light petroleum (b.p. $40-60^{\circ}$ ) to remove a yellow oil together with cholesterol, both of which were effective in inhibiting crystallization of THCA. The petroleum-washed residue was then subjected to multiple crystallizations at $4^{\circ}$ from ethyl acetate, showing the following pattern. First, crystals melting at $195^{\circ}$ appeared; after these had been collected, the supernatant solution was concentrated and kept at $4^{\circ}$ for several hours. This produced a crop of crystals melting at $172^{\circ}$. Finally, after the above procedure had been repeated, impure material melting between $180^{\circ}$ and $190^{\circ}$ was obtained. In some instances multiple crystallizations from ethyl acetate alone did not remove a yellow contamination from the crystals. This could be accomplished as follows. To the yellow-stained material, dissolved in a minimum amount of boiling ethyl acetate, was added a heaped spatula of activated charcoal. After standing for 5 min., the mix was filtered hot through two thicknesses of Whatman no. 42 filter paper and the now colourless filtrate placed at $4^{\circ}$ for crystallization. Mass-spectrographic analysis of the material melting at $172^{\circ}$ and $195^{\circ}$ respectively confirmed that both substances were $3 \alpha, 7 \alpha, 12 \alpha$-trihydroxycoprostanic acids. Since the mass spectra of each were identical, we were probably dealing here with optical isomers at C-25 as

Bioch. 1969, 114 
described by Bridgwater (1956). The physical constants of our two compounds agreed well with those reported in the literature: $3 \alpha, 7 \alpha, 12 \alpha$-trihydroxy-5 $\beta$-cholestanoic acid (25-L), m.p. $194-196^{\circ},[\alpha]_{\mathrm{D}}^{20}+43 \pm 2^{\circ}$ (c 1.81 in ethanol) [Bridgwater (1956) gives m.p. 194-196 ${ }^{\circ},[\alpha]_{\mathrm{D}}^{22}+42 \cdot 6 \pm 2^{\circ}$ ]; $3 \alpha, 7 \alpha, 12 \alpha$-trihydroxy-5 $\beta$-cholestanoic acid (25-D), m.p. $172-173^{\circ},[\alpha]_{\mathrm{D}}^{20}+27 \cdot 8 \pm 2^{\circ}(c) 1 \cdot 79$ in ethanol $)$ [Haslewood (1952) and Bridgwater (1956) give m.p. 171-173, $[\alpha]_{\mathrm{D}}^{22}$ $+27 \cdot 4 \pm 2^{\circ}$. Each substance gave a single spot when run on t.l.c. in a number of different solvent systems.

Materials. ATP (disodium salt), GSH, NAD ${ }^{+}$and $\mathrm{CoA}$ were obtained from the Sigma Chemical Co., St Louis, Mo., U.S.A. Trisodium citrate dihydrate and EDTA were products of British Drug Houses Ltd., Poole, Dorset. [4-14 C]Cholesterol (specific radioactivity $54.5 \mu \mathrm{c} / \mathrm{mg}$.) was purchased from The Radiochemical Centre, Amersham, Bucks. Immediately before use the radioactive cholesterol was purified by elution with benzene through a neutral alumina column (Woelm; Brockmann activity grade III).

Incubation conditions and extraction procedure. Livers from 10-12-week-old Wistar rats were homogenized with a loose-fitting Potter-Elvehjem homogenizer in 3 vol. of cold potassium phosphate buffer (Frantz \& Bucher, 1954), pH 7.4, containing nicotinamide $(3.6 \mathrm{mg} . / \mathrm{ml}$.). The homogenate was centrifuged at $500 \mathrm{~g}$ for $10 \mathrm{~min}$. to remove nuclei, cell debris and unbroken cells, and the supernatant suspension was then centrifuged at $20000 \mathrm{~g}$ for $20 \mathrm{~min}$. The supernatant layer from the latter centrifugation was used as a source of enzymes in the incubations. All manipulations were carried out at $0^{\circ}$.

The substrate, cholesterol, dissolved in benzene, was added in the amounts specified in Table 1 into individual $50 \mathrm{ml}$. Erlenmeyer flasks followed by $4 \mathrm{mg}$. of Tween 80 in methanol. After addition of a solution of $0.25 \mathrm{mg}$. of THCA (either the L- or the D-form) as trapping agent, the solvents were evaporated in a stream of $\mathrm{N}_{2}$ at $40-50^{\circ}$. To the warm residue was added $5 \mathrm{ml}$. of phosphate buffer, pH 7.4, and the mixture was well emulsified by shaking. After cooling, ATP (50 $\mu$ moles), $\mathrm{NAD}^{+}(7 \cdot 5 \mu \mathrm{moles}), \mathrm{CoA}$ (1.25 $\mu$ moles), trisodium citrate dihydrate ( $75 \mu \mathrm{moles})$, GSH (50 $\mu$ moles) and EDTA (27 $\mu$ moles) were added to each flask, followed by $6 \mathrm{ml}$. of enzyme (equivalent to $2 \mathrm{~g}$. of rat liver). Flasks prepared in an identical manner, except that they contained enzyme that had been boiled for $20 \mathrm{~min}$., acted as controls. The incubations were conducted aerobic-

Table 1. Melting points and specific radioactivities of THCA (25-D) isolated from the incubation mixtures

See the text for details. Each flask contained 50000 c.p.m. of [4-14C]cholesterol. THCA isolated from control flasks had negligible radioactivity. Percentage conversion of cholesterol into THCA (25-D) was 0.45.

\begin{tabular}{|c|c|c|c|}
\hline Crystallization & $\begin{array}{l}\text { Wt. } \\
\text { (mg.) }\end{array}$ & $\begin{array}{l}\text { Melting } \\
\text { point }\end{array}$ & $\begin{array}{l}\text { Sp. radioactivity } \\
\text { (c.p.m./m-mole) }\end{array}$ \\
\hline Ethyl acetate & $8 \cdot 4$ & $172-173^{\circ}$ & 52600 \\
\hline $\begin{array}{l}\text { Ethyl acetate- } \\
\text { light petroleum } \\
\text { (b.p. } 40-60^{\circ} \text { ) }\end{array}$ & 6.0 & $172-173$ & 51700 \\
\hline Ethyl acetate & $3 \cdot 2$ & $172-173$ & 54000 \\
\hline
\end{tabular}

ally for $1 \mathrm{hr}$. at $37^{\circ}$ with constant mechanical shaking. At the end of the incubation period the reaction was terminated by the addition of $40 \mathrm{ml}$. of $95 \%$ ethanol to each flask. Usually five flasks were employed per incubation. After evaporation of the total ethanol extract from the incubation mixtures, $3 \mathrm{mg}$. of carrier THCA (either the L- or the D-form) was added to the residue, which was then hydrolysed with $50 \mathrm{ml}$. of methanolic $5 \%(\mathrm{w} / \mathrm{v}) \mathrm{KOH}$ for $\frac{1}{2} \mathrm{hr}$. THCA was extracted with ether from the diluted and acidified digest after prior removal of non-saponifiable material and fatty acids respectively with light petroleum (b.p. $40-60^{\circ}$ ). The ether residue was enriched with a further $5 \mathrm{mg}$. of carrier THCA and, after dissolution in a small volume of methanol, the whole was subjected to t.l.c. in benzene-ethyl acetate $(2: 1, v / v)$ to remove unchanged labelled cholesterol. The THCA-containing band was eluted from the silica gel with hot methanol and run in benzene-propan-2-ol-acetic acid (30:10:1, by vol.) several times to separate THCA from both cholic acid and chenodeoxycholic acid. The following $R_{F}$ values were obtained: cholic acid, 0.33; THCA (both epimers), 0.53; chenodeoxycholic acid, $0 \cdot 61$. After elution of the THCA from the plate, the residue was diluted with $12 \mathrm{mg}$. of non-radioactive THCA and the whole recrystallized a number of times (Tables 1 and 2). To provide further evidence for the identity of the recrystallized material, its behaviour on t.l.c. in three different solvent systems [benzene-ethyl acetate $(2: 1, v / v)$; iso-octane-di-isopropyl ether-acetic acid (2:1:1, by vol.); benzene-propan-2-olacetic acid (30:10:1, by vol.)] was compared with that of authentic THCA. After identification of the spots by exposing them to iodine vapour for a few minutes, they were eluted from the silica gel with hot methanol, plated and dried, and their radioactivity was assayed. In all instances the material behaved like pure THCA and, further, radioactivity was detected only in those areas occupied by the material and nowhere else on the chromatogram. Radioactivity of all samples was assayed at infinite thinness in a Nuclear-Chicago gas-flow counter. Counting was continued until the error was less than $\pm 3 \%$.

\section{RESULTS AND DISCUSSION}

Evidence derived from a number of different sources has indicated that THCA, the principal bile acid in crocodilians, might be an intermediate in the biosynthesis of bile acids from cholesterol in mammals. Bridgwater \& Lindstedt (1957) noted

Table 2. Melting points and specific radioactivities of THCA (25-L) isolated from the incubation mixtures

See the text for details. Percentage conversion of cholesterol into THCA (25-L) was 0.1.

\begin{tabular}{|c|c|c|c|}
\hline Cryst & $\begin{array}{l}\text { Wt. } \\
\text { (mg.) }\end{array}$ & $\begin{array}{l}\text { Melting } \\
\text { point }\end{array}$ & $\begin{array}{l}\text { Sp. radioactivity } \\
\text { (c.p.m./m-mole) }\end{array}$ \\
\hline & $6 \cdot 8$ & $192-193^{\circ}$ & 15300 \\
\hline $\begin{array}{l}\text { Ethyl acetate- } \\
\text { light petroleum } \\
\text { (b.p. 40-60 ) }\end{array}$ & 5 & $193-194$ & 12900 \\
\hline Ethyl acetate & 3.7 & 193-194 & 12600 \\
\hline
\end{tabular}


that THCA was an efficient precursor of cholic acid in the bile-fistulated rat. Mouse liver homogenates can transform $3 \alpha, 7 \alpha, 12 \alpha$-trihydroxy-5 $\beta$-cholestane, a probable intermediate in bile acid formation in mammalian liver (Mendelsohn \& Staple, 1963), into THCA (Danielsson, 1960). Similar results obtained with a rat liver preparation were reported by Suld, Staple \& Gurin (1962). After administration of [26-14C]cholesterol to a patient with a bile fistula, Staple \& Rabinowitz (1962) isolated a radioactive fraction from the bile that crystallized to constant specific radioactivity when mixed with authentic THCA. Carey \& Haslewood (1963) crystallized the methyl ester of naturally occurring THCA from human bile, thus providing definite evidence that THCA is a natural constituent of human bile. Finally, human bile-fistulated patients formed radioactive THCA after intravenous administration of [4-14C]cholesterol; the former compound, when given to another bile-fistulated patient, was converted into cholic acid (Carey, 1964).

Although the findings presented above considerably strengthen the case for THCA being an intermediate during the biosynthesis of cholic acid from cholesterol in mammals, the evidence still remains of an indirect nature. We have recently described a preparation from rat liver that can enzymically convert cholesterol into cholic acid in vitro (Mendelsohn, Mendelsohn \& Staple, 1966). In the present work the same system was employed to study the biosynthesis of THCA from cholesterol. As shown in Table 1, rat liver can metabolize cholesterol to THCA in vitro. This finding lends further considerable support to the contention that THCA is probably a normal and obligatory intermediate on the cholesterol to bile acid pathway in the rat.

Another point arising out of the results of the present investigation is the fact that label from the substrate cholesterol was incorporated to a much smaller extent into the L-form of THCA than into the D-form (Tables 1 and 2). Although both epimers of THCA have been isolated from natural sources, namely Rana catesbiana (Mabuti, 1941), Rana nigromaculata nigromaculata (Komatsubara, 1954) and Crocodylus niloticus (present paper), Haslewood (1967) has expressed the opinion that the drastic hydrolysis procedure involved during the preparation of the bile might possibly have caused some epimerization at C-25. If this is in fact the case, then one cannot be certain whether both epimers of THCA occur naturally. Staple \&
Rabinowitz (1962) and Carey \& Haslewood (1963) both isolated the D-form of THCA from human bile. The system used in vitro in the present study apparently preferred to metabolize cholesterol to the D-form, since the specific radioactivity of the latter isolated from the incubation mixtures was about four times that of L-THCA. The above findings taken together suggest that D-THCA is the naturally occurring epimer and that L-THCA might be an artifact brought about by the severe conditions used to extract these acidic sterols from bile. This question could probably best be resolved by subjecting frog or crocodile bile to a mild hydrolysis procedure (e.g. enzymic) followed by extraction and characterization of the isolated sterols.

Finally, with regard to the role played by THCA in bile acid genesis, evidence to date indicates that this compound is an intermediate in both man and rat. Whether the same applies to other species having cholic acid as their primary bile acid remains to be determined.

Due acknowledgement is made to the Atomic Energy Board and the Council for Scientific and Industrial Research for the assistance and support enabling the research concerned to be undertaken, and for permission to publish the results of the work. We also thank Dr H. J. Heinz for the crocodile bile and Dr K. G. R. Pachler for the mass-spectrographic analyses.

\section{REFERENCES}

Bridgwater, R. J. (1956). Biochem. J. 64, 593.

Bridgwater, R. J. \& Haslewood, G. A. D. (1952). Biochem.J. $52,588$.

Bridgwater, R. J. \& Lindstedt, S. (1957). Acta chem. scand. 11, 409.

Carey, J. B., jun. (1964). J. clin. Invest. 43, 1443.

Carey, J. B., jun. \& Haslewood, G. A. D. (1963). J. biol. Chem. 238, 855.

Danielsson, H. (1960). Acta chem. scand. 14, 348.

Frantz, I. D. \& Bucher, N. L. (1954). J. biol. Chem. 206, 471.

Haslewood, G. A. D. (1952). Biochem. J. 52, 583.

Haslewood, G. A. D. (1967). Bile Salts, p. 16. London: Methuen and Co. Ltd.

Komatsubara, T. (1954). Proc. imp. Acad.Japan, 30, 618. Kurauti, Y. \& Kazuno, T. (1939). Hoppe-Seyl. Z. 262, 53.

Mabuti, H. (1941). J. Biochem., Tokyo, 33, 131.

Mendelsohn, D., Mendelsohn, L. \& Staple, E. (1966). Biochemistry, 5, 3194.

Mendelsohn, D. \& Staple, E. (1963). Biochemistry, 2, 577.

Staple, E. \& Rabinowitz, J. L. (1962). Biochim. biophys. Acta, 59, 735.

Suld, H. M., Staple, E. \& Gurin, S. (1962). J. biol. Chem. 237, 338. 